\title{
CAT PARAHIPPOCAMPAL UNIT DISCHARGE PATTERNS DURING LIMBIC STIMULATION
}

\author{
PETER COYLE* \\ Department of Anatomy, University of Michigan, Ann Arbor, Mich. 48104 (U.S.A.)
}

(Accepted March 25th, 1969)

\section{INTRODUCTION}

The cat parahippocampal gyrus, a part of the limbic lobe of Broca $^{4}$, includes the subicular and entorhinal areas ${ }^{\mathbf{1 4}, 19}$. The septum, hippocampus, and cingulate gyrus may project fibers directly to these areas ${ }^{1,6-8,15-18,24}$ in various animals including cat. Commissural fibers from one entorhinal area pass to the contralateral homotopic cortex ${ }^{3}$. These anatomical studies suggest paths from different limbic structures transmit signals which converge on parahippocampal units. The influences on unit spike patterns are not known. The intent of this study was to investigate the types of input (excitatory, inhibitory) resulting from a regional limbic stimulation. Patterns resulting from inputs simultaneously arising in different limbic structures and the stimulus parameters affecting the inputs are subjects for future study. Specifically, units were tested for stimulus time-locking or entrainment of their firings to electrical stimuli.

\section{METHODS AND MATERIALS}

Thirty-five cats weighing between 2 and $3.5 \mathrm{~kg}$, unselected as to sex, were sampled. With the benefit of ether anesthesia, a tracheotomy was performed. The animal was then placed in a stereotaxic frame. The animal's skull was exposed, trephine holes were drilled and the dura reflected where necessary. Concentric bipolar electrodes were lowered (Fig. 1) into the septal area, middle of the anterior-posterior extent of the supracallosal cingulum, and most posterior extent of the hippocampus ipsilateral to the side of the unit being studied. An electrode was placed in the middle of the vertical extent of the contralateral parahippocampal gyrus. The trephine holes were filled with agar gel to help stabilize the brain. Mineral oil was placed in the conjunctival sacs. All incision and pressure points were infiltrated with procaine hydrochloride anesthetic and the ether was withdrawn. Sufficient amounts of D-

* This study represents in part a dissertation submitted in partial fulfillment of the requirements for the degree of Doctor of Philosophy at the University of Michigan, 1967. 


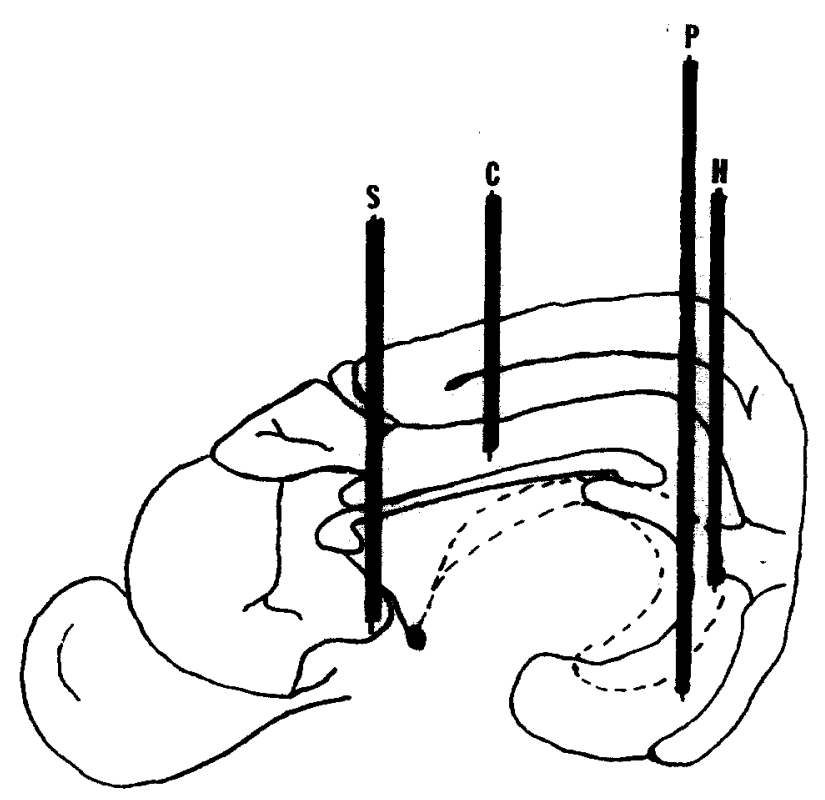

Fig. 1. Illustration showing locations of stimulating electrodes. Reference planes given in Snider and Niemer ${ }^{20}$ atlas. Locations of electrodes: septal (S) A 15.0, L 1.0, V +3.0, cingulum (C) A 8.5, L 2.0, $\mathrm{V}+11.0$, hippocampus (H) A 1.5, L 12.0, V +6.0, parahippocampal gyrus (P) A 4.2, L 11.2, V -5.0.

tubocurarine were administered to immobilize the animal. Artificial ventilation was employed. A hot water bottle was utilized to help maintain body temperature. A minimum of $2 \mathrm{~h}$ elapsed between the time of the ether removal and the start of unit recordings.

Stainless steel microelectrodes ${ }^{10}$ were stereotaxically placed in the right subicular area. Adjustment of the microelectrode tip position was carried out until a firing unit was located either in the subiculum or underlying entorhinal area. The unit's electrical activity was coupled to a cathode follower and amplified by a Grass P 6 preamplifier. Care was taken to record from only one unit at a given time. The unit had to show a 1-2 msec spike with a good signal to noise ratio. No data were included where more than one unit was monitored at a given time. The unit's spike triggered a Tektronix Type 161 Pulse Generator which was connected to the intensity modulation unit of an oscilloscope. A periodic pulse initiated the beam sweep and stepped the output of a linear staircase generator. Output of the staircase generator was applied to the $\mathrm{Y}$-axis amplifier ${ }^{5}$, preventing masking of events. A bright spot formed on the oscilloscope screen each time the unit fired. Time exposure pictures were taken of the displays.

Bipolar pulses of $0.3-\mathrm{msec}$ duration were presented at only one electrode during a $10-\mathrm{sec}$ stimulation period. The other 3 electrodes were used to monitor limbic electrical activity. During a given period the stimulation frequency was constant, but varied between 2 and $10 / \mathrm{sec}$ for the experimental series. No data were included for trials which resulted in a monitored limbic electrical seizure. When less than supramaximal stimulations are used larger variations of active neurons in the 


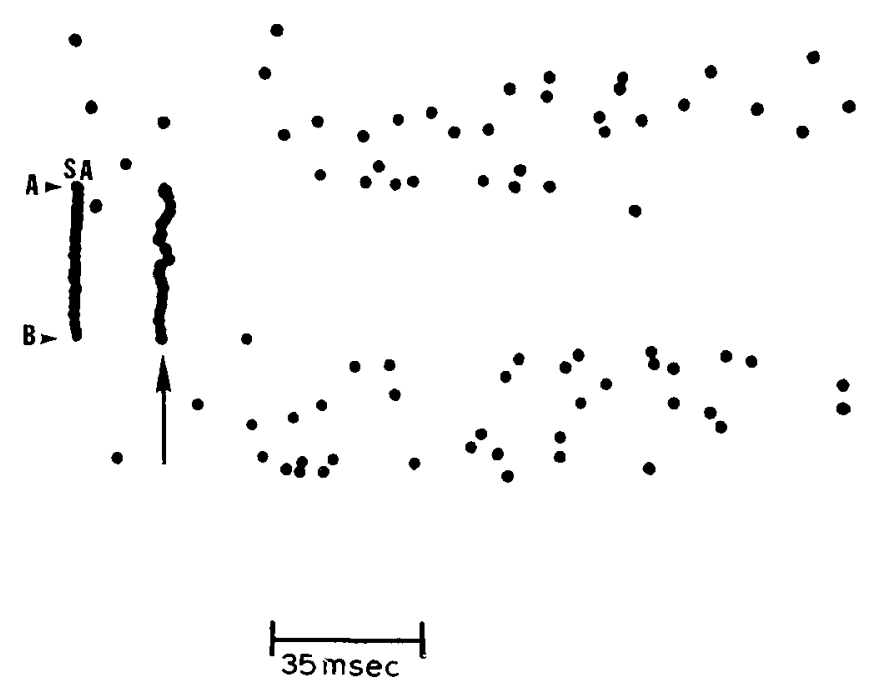

Fig. 2. Reproduction of a time exposure of oscilloscope data showing a unit's discharge patterns for $10 \mathrm{sec}$ before, during, and after septal stimulation at slightly less than $5 / \mathrm{sec}$. Beam sweep left to right. Before and following stimulation period (above $A$ and below $B$ ) unit fired with a random time relationship to the sweep initiation, During period of stimulation (A to B) unit generally fired only once per stimulus as is indicated by the time-locked response column (arrow) and by absense of dots on each side of the response column. Left-hand column is stimulus artifact (SA).

\section{TABLE I}

PARAHIPPOCAMPAL UNIT ACTIVITY DURING LIMBIC STIMULATION

\begin{tabular}{|c|c|c|c|}
\hline $\begin{array}{l}\text { Septum } \\
\text { (nuc. medialis } \\
\text { anterior) }\end{array}$ & $\begin{array}{l}\text { Hippocampus } \\
\text { (CA4 pyramids) }\end{array}$ & Cingulum & $\begin{array}{l}\text { Parahippocampal } \\
\text { gyrus } \\
\text { (small pyramids) }\end{array}$ \\
\hline
\end{tabular}

Number of units tested

(total population $=138$ )

Number of units with one entrained firing

114

30

Number of units with multiple entrained firings Other locations evoking entrained firing(s) from same units Latency to first entrained firing (msec)
Number of units stopped firing

$\begin{array}{lccc}14 & 109 & 100 & 88 \\ 30 & 6 & 4 & 10 \\ 10 & 2 & - & 2 \\ \text {-parahipp } & \text { 5-sept } & \text { 2-hipp } & 8 \text {-sept } \\ \text {-hipp } & \text { 2-cing } & & \\ 17 & 5 & - & - \\ -45 & 5-10 & 10-20 & 50-80\end{array}$

sampled population can be expected ${ }^{11}$. In order to minimize population variations as much as possible the magnitude of the stimulus intensity was adjusted to be just above threshold for inducing a maximum evoked response from the hippocampus, as recorded from the hippocampal electrode.

Upon completion of the unit recording a DC current was passed through the 

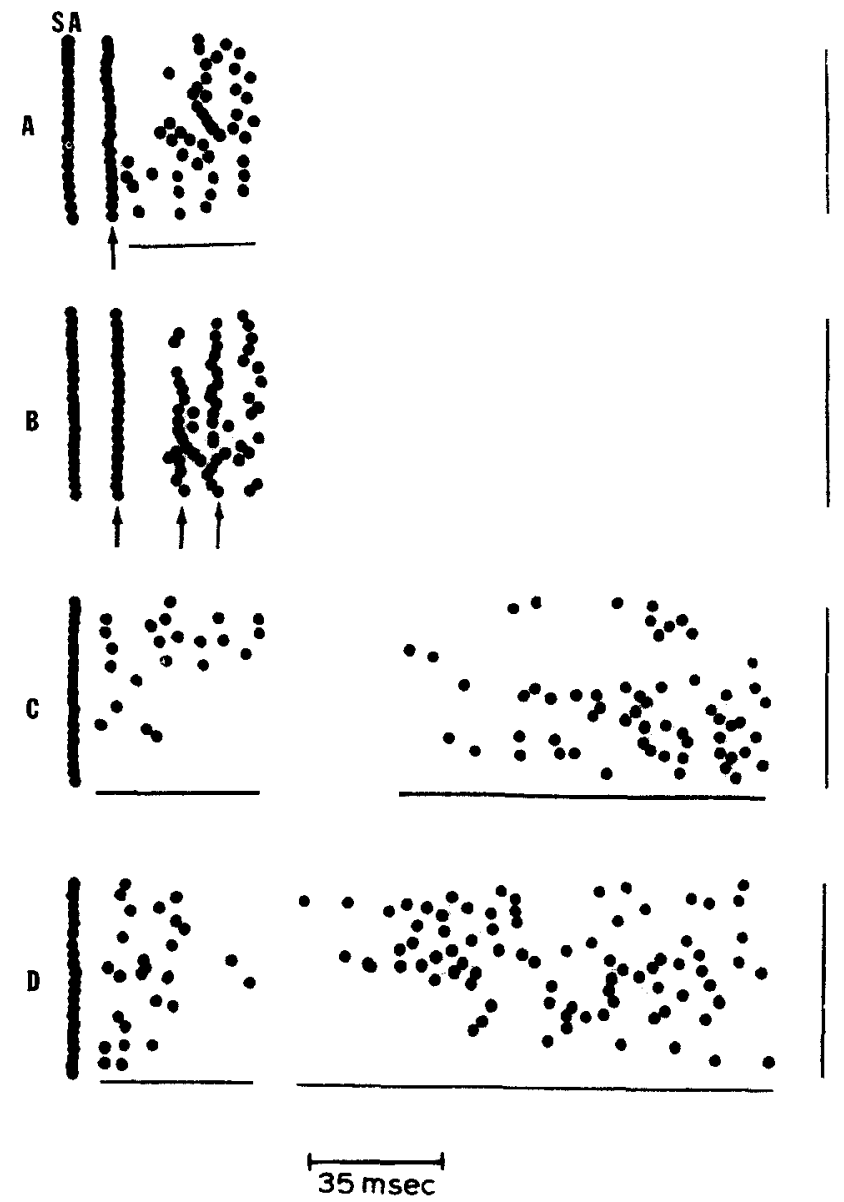

Fig. 3. A, B, C, D, Reproduction of a time exposure of oscilloscope data showing discharge patterns of the same unit during stimulation at different limbic locations. Beam sweep left to right. Stimulation rate slightly less than 5/sec. Left-hand column is stimulus artifact (SA). Arrows indicate time-locked firings. First septal stimulation period (A) shows time-locked firing is followed by an interval (horizontal bar) during which time-preferred firings occurred. A $150-\mathrm{msec}$ non-firing period follows. During the second septal stimulation period (B) (same stimulus parameters as during A) timelocked spikes occurred. During the second hippocampal (C) and the second cingulum (D) stimulation periods time-preferred spikes occurred (horizontal bars denote 2 intervals).

microelectrode. At the end of the experiment the animal was perfused with a solution ${ }^{12}$ which enabled identification of small iron deposits, indicating unit recording locations. Paraffin sections $20-40 \mu$ in thickness were stained with basic fuchsin ${ }^{21}$. The tissue locations of the electrode tips were histologically investigated.

RESULTS

Unit spikes were counted for a 5-sec epoch just prior to stimulation. The average spike frequency for a group of 102 cells ( 757 samples) was $4.2 / \mathrm{sec}$.

The units were tested for spike entrainment by limbic stimuli. Unit firings were 
classified as being entrained or stimulus time-locked if they occurred with nearly the same latency following consecutive stimuli. Fig. 2 exemplifies firings entrained by septal stimuli. For the example, one firing generally occurred for each stimulus presentation. Other units fired either single or multiple spikes time-locked to stimuli (Figs. 3B and 5B). Table I lists the number of units usually firing with either single or multiple firings time-locked to stimulus presentations at the different limbic locations. A small number of units were entrained by stimuli presented at more than one location. More units ( 40 out of 114) were entrained by septal stimuli than by other limbic stimuli.

Latencies were measured from stimuli to the first time-locked interstimulus firing. Different units fired with different latencies during stimulation at a given limbic location. For the group of units, Table I lists the range of latencies. No unit classification relating a given latency or firing configuration to a specific cortical location in the parahippocampal gyrus could be made. Of the 138 units sampled 126 recording sites were located. Sixty-seven sites were in the more lateral part of the entorhinal area, whereas 59 subicular sites were closer to CA1 of the hippocampus than to the entorhinal area.

Some units stopped firing during limbic stimulation periods. Most stopped firing during the $1 \mathrm{st} \sec$ of stimulation, whereas a few stopped later in the stimulation

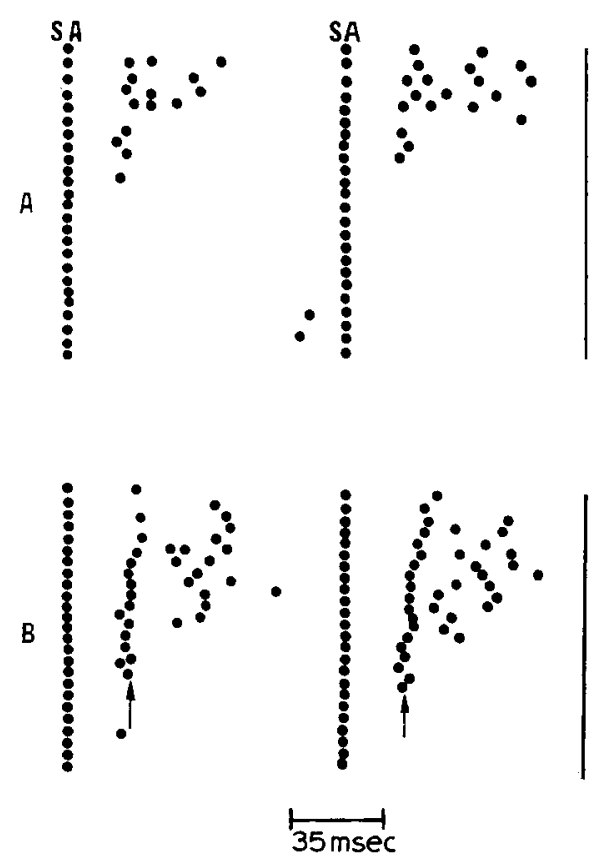

Fig. 4. A, B, Reproduction of oscilloscope data showing changing firing patterns during $10 / \mathrm{sec}$ septal stimulation. Beam sweep left to right. Two stimulus artifacts (SA) for each sweep. A shows unit fired with time-preferred spikes. During last one-half of stimulation period unit fired twice. B shows the same unit fired time-locked spikes (arrows) to similar stimuli as presented during A. Time-locked firing latency decreased during stimulation period. Unit fired once during last quarter of stimulation period. 
period (Figs. 4A and B). More units (17) stopped firing during septal stimulation than during hippocampal stimulation. Units frequently did not fire for periods up to $5 \mathrm{sec}$ following the last stimulus presentation. No unit stopped firing during cingulum or left parahippocampal gyrus stimulation.

Not all firings were stimulus time-locked in the strictest sense of the meaning (Figs. 3C and D). The examples illustrate configurations where the repeated evoked firings occurred during a time segment rather than at a point in time following the stimuli. That is to say, there was more variation in the time before the response than if the response was strictly time-locked. Such firings could be classified as stimulus time-preferred firings. Attempts were not made to make a tally of units discharging with time-preferred spikes. Classification of firings as time-preferred spikes is particularly difficult when the firing time variation is large.

Firing patterns such as those in Figs. $3 \mathrm{~A}$ and $4 \mathrm{~B}$ demonstrate stimulus timelocked and time-preferred spikes. The configurations were different during consecutive 10-sec periods of septal stimulation. For example, in Fig. $3 \mathrm{~A}$ the timepreferred firings followed the time-locked firings. During the next stimulation period (Fig. 3B), approximately $1 \mathrm{~min}$ after the termination of the previous one, more of the firings were time-locked. Other units discharging only time-preferred
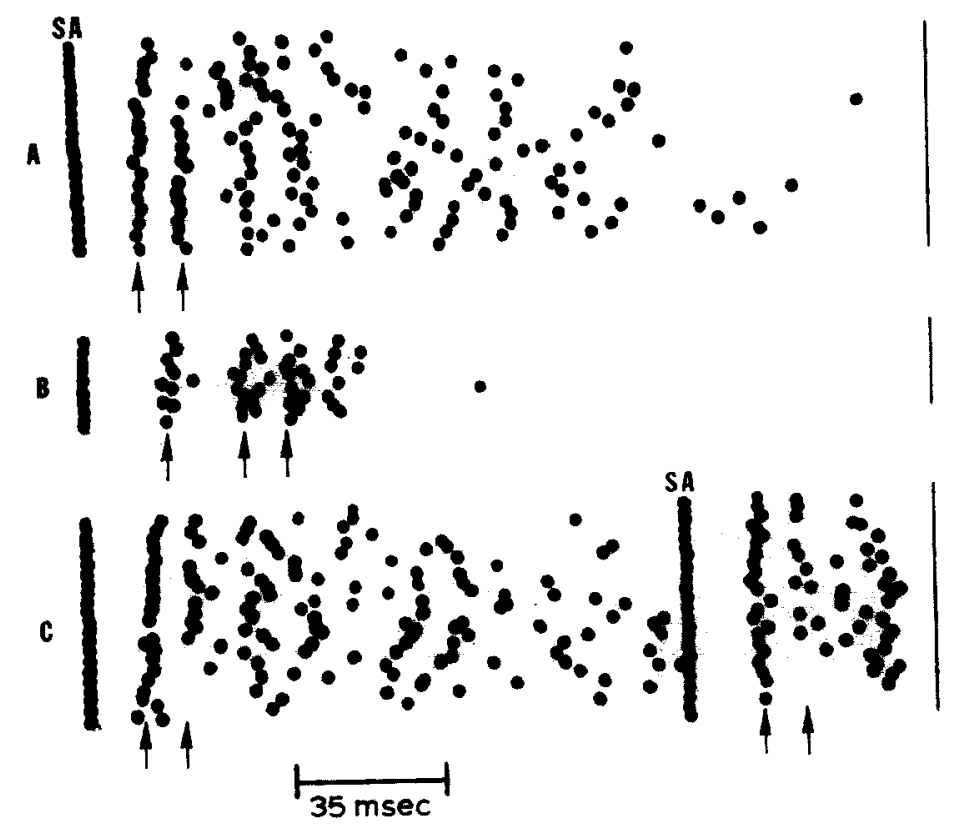

Fig. 5. A, B, C, Reproduction of oscilloscope data showing different unit patterns during consecutive septal stimulation periods. Beam sweep left to right. Stimulus artifact columns (SA). Arrows indicate time-locked firings. A shows unit fired nearly time-locked to the stimulus during stimulation at $5 / \mathrm{sec}$. Other non-time-locked spikes followed. For the same unit B shows a longer latency until the timelocked firings during stimulation at $2.5 / \mathrm{sec}$. Fewer non-time-locked spikes occurred. Stimulations at $7 / \mathrm{sec}(\mathrm{C})$ resulted in patterns nearly similar to those evoked during stimulation at $5 / \mathrm{sec}$. 
spikes during the first septal stimulation period (Fig. 4A) discharged time-preferred and time-locked spikes during the following stimulation period (Fig. 4B).

Spike latencies frequently decreased as the period of septal, but not other limbic, stimulations progressed. Variations in latencies of discharges following consecutive stimuli were small (Figs. 4B and 5A). However, spikes occurring at the beginning and towards the end of stimulation periods differed as much as $15 \mathrm{msec}$ in latency. No spike latency times increased as the stimulation periods progressed.

The number of firings per stimulus and latencies of entrained spikes of 3 units were governed by the frequency of septal stimuli. Stimulating at $2.5 / \mathrm{sec}$ (Fig. 5B) resulted in time-locked spikes having longer latencies than spikes entrained by stimuli presented at $5 / \mathrm{sec}$ (Fig. 5A). During stimulation at the lower frequency, fewer time-preferred spikes occurred. Stimulating at $7 / \mathrm{sec}$ (Fig. $5 \mathrm{C}$ ) evoked nearly the same patterns as stimulations at $5 /$ sec.

\section{DISCUSSION}

The parahippocampal unit entrained firings may have represented an orthodromic mode of activation, an antidromic invasion, or a rebound phenomenon ${ }^{13}$. Current spread, projections having different conduction rates, and conduction over paths of different lengths may account for the widespread range of time-locked firing latencies for different units during stimulation at a given limbic location.

Units firing with latencies which decreased as the septal stimulation period progressed were probably activated by orthodromically traveling spikes. That timelocked spikes were present at latency times where time-preferred spikes occurred during a preceding stimulation period indicates septal stimulation facilitates a less variable pattern of discharge. The underlying regulating mechanisms are obscure. Pattern alterations as functions of the septal stimulation parameters need further study. Possibly, transmitter substance was primed for release; with reduced delays through multisynaptic paths spike driving rates became limited, resulting in more time-locked firings and shorter latencies.

Hippocampal units can be driven by septal stimuli ${ }^{9}$. Direct septal-parahippocampal projections $s^{6,16}$ and multisynaptic paths, passing from the septum via the fornix to the hippocampal formation ${ }^{22,23}$ and thence by hippocampal recurrent collaterals to parahippocampal units ${ }^{15,18}$ were most likely activated by septal stimuli. Septal excitations fired some units and stopped discharges from others. Thus, inputs to the hippocampus and dentate gyrus transmitted via parahippocampal arising temporo-ammonic and perforating tract fibers ${ }^{15,18}$ are probably regulated in part by septal activity.

Conversely, during cingulum or left parahippocampal gyrus stimulation, no unit tested stopped firing. Impulses passing over these limbic structures to enter the parahippocampal gyrus $1,3,6,17,24$ may not block transmission of, but contribute to, signals presumably entering the hippocampus and dentate gyrus. Cingulum and left parahippocampal gyrus signal contributions may not block parahippocampal signals leading those of the hippocampus in the fully trained cat ${ }^{2}$, whereas the septum and 
possibly the hippocampus may regulate, by excitatory and inhibitory influences, inputs to the hippocampus.

SUMMARY

Previous anatomical studies have demonstrated various limbic projections to the parahippocampal gyrus. The influences on parahippocampal units resulting from impulses passing over these fibers are unknown. Units were tested for spike entrainment or time-locking to a restricted regional limbic excitation. More units (40 out of 114) were entrained by septal stimuli than by hippocampal, cingulum, or contralateral parahippocampal gyrus stimuli. Some units fired one time-locked spike while others fired multiple spikes for each stimulus. Time-preferred spikes, varying more in latency than time-locked spikes, were discharged by other units. Pattern changes during septal stimulation suggest multisynaptic paths were involved. During separate periods of septal and hippocampal stimulation a number of units stopped firing. These units frequently did not fire for periods lasting up to $5 \mathrm{sec}$ following the last stimulus. It is concluded the septum, possibly by way of the hippocampus, exerts excitatory and strong inhibitory influences on parahippocampal units. Signals passing over the cingulum and contralateral parahippocampal gyrus may contribute to, but possibly do not block, inputs entering the hippocampus via parahippocampal projections.

\section{ACKNOWLEDGEMENTS}

The author wishes to thank Dr. Charles L. Votaw, in whose laboratory this project was undertaken, for advice and encouragement during this work. The author received support from the N.I.H. Anatomical Training Grant GM 312 and the project was developed under support from N.I.H. NB 05069, Dr. Votaw, chief investigator.

\section{REFERENCES}

1 ADEY, W. R., An experimental study of the hippocampal connexions of cingulate cortex in rabbit, Brain, 74 (1951) 233-247.

2 Adey, W. R., Dunlop, C. W., And Hendrix, C. E., Hippocampal slow waves. Distribution and phase relationships in the course of approach learning, Arch. Neurol. (Chic.), 3 (1960) 74-90.

3 BLACKSTAD, J. W., Commissural connections of the hippocampal region in the rat with special reference to their mode of termination, $J$. comp. Neurol., 105 (1956) 417-538.

4 Broca, P., Sur la circonvolution limbique et la seissure limbique, Bull. Soc. anthr. Paris, Ser 2, 12 (1877) 646-657.

5 COYle, P., AND Votaw, C. L., Use of a linear staircase generator in displaying synchronized pulse activity, Rev. sci. Instr., 39 (1968) 1381-1382.

6 Cragg, B. G., Afferent connexions of the allocortex, J. Anat. (Lond.), 99 (1965) 339-357.

7 Cragg, B. G., ANd Hamlyn, L. H., Some commissural and septal connexions of hippocampus in rabbit. A combined histological and electrical study, J. Physiol. (Lond.), 135 (1957) $460-485$.

8 CRAGG, B. H., AND HAMLYN, L. H., Histologic connections and electrical and autonomic responses evoked by stimulation of the dorsal fornix in the rabbit, Exp. Neurol., 1 (1959) 187-213. 
9 Euler, C. von, And Green, J. D., Excitation, inhibition and rhythmical activity in hippocampal pyramidal cells in rabbit, Acta physiol. scand., 48 (1960) 110-125.

10 GreEN, J. D., A simple microelectrode for recording from the central nervous system, Nature (Lond.), 182 (1958) 962.

11 Green, J. D., The hippocampus, Physiol. Rev., 44 (1964) 561-608.

12 Green, J. D., Mancia, M., AND Von Baumgarten, R., Recurrent inhibition in the olfactory bulb. I. Effects of antidromic stimulation of the lateral olfactory tract, J. Neurophysiol., 25 (1962) 467-488.

13 Kandel, E. R., ANd Spencer, W. A., Electrophysiology of hippocampal neurones. II. Afterpotentials and repetitive firing, $J$. Neurophysiol., 24 (1961) 243-259.

14 LoRente de Nó, R., Studies on the structure of the cerebral cortex. I. The area entorhinalis, J. Psychol. Neurol., 45 (1933) 381-438.

15 LoREnte de Nó, R., Studies on the structure of the cerebral cortex. II. Continuation of the study of the ammonic system, J. Psychol. Neurol., 46 (1934) 113-177.

16 Powfll, E. W., Septal efferents in the cat, Exp. Neurol., 14 (1966) 328-337.

17 Raisman, G., Cowan, W. M., ANd POwell, T. P. S., The extrinsic afferent, commissural and association fibres of the hippocampus, Brain, 88 (1965) 963-996.

18 Ramón y Cajal, S., Histologie du Système Nerveux de l'Homme et des Vertébrés, Vol. II, Maloine, Paris, 1909-1911, pp. 702-703.

19 SMith, R. W., AND WhITE, L. E., The fiber architectonics of the cat hippocampal formation, J. comp. Neurol., 123 (1964) 11-27.

20 Snider, R. S., And Niemer, W. T., A Stereotaxic Atlas of the Cat Brain, Univ. Chicago Press, Chicago, 1961.

21 Szabó, I., Combined staining of central nervous system tissue with luxol fast blue and basic fuchsin, Acta morphol. Acad. Sci. hung., 13 (1965) 251-254.

22 Votaw, C. L., Study of septal stimulation and ablation in the macaque monkey, Neurology (Minneap.), 10 (1960) 202-209.

23 Votaw, C. L., AND Lauer, E. W., An afferent hippocampal fiber system in the fornix of the monkey, J. comp. Neurol., 121 (1963) 195-206.

24 WhITE, L. E., Ipsilateral afferents to the hippocampal formation in the albino rat. I. Cingulum projection, J. comp. Neurol., 113 (1959) 1-41. 